\title{
Varicella-Zoster Virus Reactivation amid the COVID-19 pandemic- Do we need to be vigilant? A mini review
}

\author{
Mishal Shan Siddiqui, Nimra Hasnain \\ Dow Medical College, Dow University of Health Sciences (DUHS), Karachi, Pakistan
}

Received: 2020-08-10.

Accepted: 2020-10-16

This work is licensed under a

Creative Commons Attribution 4.0 International License

J Clin Med Kaz 2020; 6(60):40-43

Corresponding author:

Nimra Hasnain.

E-mail: nimra.hasnain29@gmail.com; ORCID:

\section{Abstract}

Reactivation of varicella-zoster infection has been noted in a subset of COVID-19 patients. This has been attributed to immune dysregulation resulting from SARS-CoV-2 infection. Majority individuals presented with shingles, however, neurological complications such as meningoencephalitis and acute retinal necrosis were also reported. Diagnosis in most cases was made on clinical grounds, however, for complications such as meningoencephalitis, the standard investigative measures such as polymerase chain reaction tests (PCR) were conducted. Post-herpetic neuralgia (PHN), a less common sequel of shingles, was witnessed despite the early administration of therapy. Most cases were resolved with antiviral therapy; however, in some instances, corticosteroids had to be administered.

Key words: herpes zoster, COVID-19, acyclovir, ganciclovir

\section{Introduction}

SARS-CoV2, the causative agent of the COVID-19 pandemic, is a member of the Coronoviridae family which includes single-stranded RNA viruses. Similar strains such as SARS-COV and MERS-COV have also been involved in major outbreaks and are evidenced to demonstrate widespread systemic damage. The virus is associated with mortality rates between $3-4 \%$ and imposes a greater risk of morbid outcomes in the elderly, immunocompromised individuals, and those with underlying risk factors such as obesity, diabetes, and hypertension [1].

This virus presents with a cluster of heterogeneous symptoms involving the respiratory, gastrointestinal, and nervous systems $[2,3,4]$. Skin involvement in COVID-19 is also hypothesized to occur. This may be due to direct immune damage by SARS-COV2, or indirectly as a manifestation of systemic involvement [5,6]. Skin symptoms range from widespread erythema, urticaria, and varicella-like rash in a subset of individuals. Some asymptomatic individuals have demonstrated similar findings before the development of the typical COVID-19 presentation [7-10]. However, the reactivation of the Varicella-Zoster virus (VZV) is a peculiar finding. The causative agent, Varicella-Zoster Virus (VZV), latently infects the sensory ganglia after the primary exanthem of Chickenpox, usually acquired in childhood. This virus has the propensity to reactivate and cause an excruciatingly painful vesicular eruption along the affected dermatome, which may even precipitate the debilitating sequelae of post-herpetic neuralgia [11].

We, hereby, present a brief review of the occurrences of VZV reactivation in COVID-19 patients.

\section{Pathogenesis}

SARS-COV2 results in a hyperinflammatory state [12] and the subsequent immune dysregulation is postulated to be the potential cause of reactivation. The reactivation is attributed to the immune dysregulation resulting from hyperinflammatory states due to SARS COV-2. Earlier accounts of leukopenia and lymphopenia in COVID-19 patients [13] propose that a reduction in lymphocytes, predominantly CD3 and CD8 cells, may have given rise to the reactivation [14]. Additionally, a low lymphocyte count predisposes the elderly population to an eruption [15]. Moreover, Li et al. stated that a lower CD4 count or derangement in cellular function appears to result in a more dismal prognosis (Figure 1) [16]. 


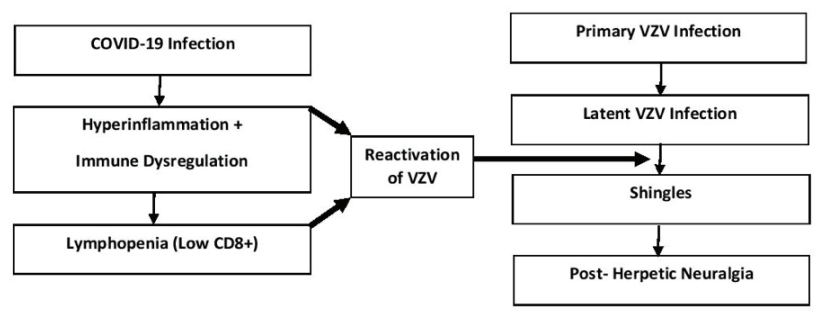

\section{Clinical features and epidemiology}

Case reports around the globe have reported the reactivation of herpes zoster in patients with evidence of COVID-19, with or without the typical respiratory symptoms. Although considered to be a disease of old [17] and immunosuppressed individuals, the younger immunocompetent people were not entirely spared from the infection in the setting of COVID-19 [18]. The number of reports was not sufficient to establish a gender predilection nor could they assess any association between comorbidities and the virus' reactivation. Nevertheless, some patients had a positive history of hypertension [18-20]. The diagnoses were made clinically except in a few where VZV serology was performed [21]. Some were asymptomatic for COVID-19, while in others the eruptions followed, with varying time intervals between the COVID-19 symptoms and reactivation, across the studies.

In a case series from Italy, four critically ill elderly patients developed herpes zoster, three of which had necrotic lesions. Intriguingly, one of the patients who was on immunosuppressive drugs due to a cardiac transplant had the least complicated clinical picture. This contrasts with the fact that immunosuppression is held as a risk factor for reactivation. However, all four patients had lymphopenia, especially decreased CD8+ and CD3+ cells, which might have contributed to the cessation of latency [22]. Lymphopenia was also observed in a 58-year-old male from Massachusetts, who developed meningitis in addition to shingles. He complained of severe headaches and abdominal symptoms before the development of a rash. Typical chest symptoms and meningitis followed several days later [23].

Elsaie et al. mentioned another such case in which respiratory symptoms of COVID-19 and ground-glass opacities on the computed tomography (CT) scan appeared two days after the development of vesicles. This patient was a 68-year-old hypertensive male whose rash later turned hemorrhagic. Another case was that of a 60-year-old hypertensive female who had been experiencing dyspnea for five days before the onset of rash, but this was interpreted as a seasonal allergy by her attendants. She was tested positive for COVID-19 after the development of vesicles [19].

A 39-year-old-male from Brazil, with no significant history, had been experiencing fatigue and diarrhea for 10 days, after which he developed pain in the trigeminal distribution. Vesicular lesions followed 3 days after the development of neuralgia. His white blood cell count and $\mathrm{C}$ - reactive protein were in the normal ranges. Surprisingly, his IgM serology was positive for VZV even though he had a history of chickenpox in childhood [21].

Herpes zoster has also been reported to occur after the appearance of typical COVID-19 symptoms, as reported by Saati et al. The 57-year-old, previously hypertensive, male developed shingles of the T4 dermatome after experiencing cough, shortness of breath, headache, anosmia, and ageusia for four days. However, he had no history or laboratory investigations to suggest an immunosuppressed state. The only abnormality was a slight ESR and a C-reactive protein (CRP) elevation [18]. Another 44-year-old male from Egypt developed zoster, about a week after he was diagnosed with mild COVID-19 infection [24].

Another patient from the USA, a 49-year-old woman, and developed a zoster rash along the maxillary division of the trigeminal nerve. This patient had been experiencing a fever for 6 days before the eruption without any respiratory symptoms before or during her course of illness [25].

Pona et al. narrated a case of a 70-year-old female with a history of hypertension and Diabetes mellitus who developed a dermatomal rash seven days after experiencing COVID-19 related symptoms such as fever, cough, and shortness of breath. Her rash later developed a hemorrhagic crust. However, her laboratory investigations revealed a normal WBC count [20].

Ertugrul reported that a hospital in Turkey witnessed an approximately two-fold increase in the number of shingles cases during May-Jun 2020 compared to the previous year. $\mathrm{He}$ suspected that this unexplained rise might be attributed to subclinical COVID-19. However, no COVID-19 swabs were taken from people who did not show the typical COVID-19 features at the initial presentation. Thus, the degree of doubt remains [26].

\section{Severity of the lesions/ complications}

Reactivation lesions displayed varying degrees of severity and post-herpetic neuralgia was observed in two of them $[21,25]$, although elderly and immunocompromised populations are more vulnerable to developing PHN [27,28,29]. Wei et al. hypothesized that lower CD8 T- cell lymphocytes in old individuals might have an association with the development of PHN, whereas the actual mechanism is not known [15]. Immunosuppressed and those with HIV are at a higher risk of developing the necrotic zoster type. However, the incidence of this type in healthy individuals indicates the decrement of immune cells, B and T-lymphocytes, and Natural Killer cells by COVID-19 [30]. Shors et. al demonstrated that timely initiation of antiviral therapy could not prevent the incidence of PHN [25]. This prompts the clinicians to explore the risk factors and look into alternative drug regimens. Patel accounted for encephalitis in an 83-year-old individual with coexisting comorbidities who have been diagnosed with COVID-19 a week before. The characteristic involvement of the medial temporal lobe on the left side on magnetic resonance imaging (MRI) was followed by confirmation on the cerebrospinal fluid analysis (CSF) analysis. Immunosuppression was speculated to be the cause, although, there was no history of corticosteroids use. Subarachnoid hemorrhage secondary to an aneurysm and spinal cord infarcts were additionally reported, both attributed to the deranged coagulation mechanism resulting from either VZV or SARSCOV-2, or both [31].

Hassanpour reported a case of acute retinal necrosis in a COVID-19 patient following an episode of meningoencephalitis caused by reactivation of VZV. The diagnosis was initially made on radiological investigations with CSF PCR negative for the strain; however, the PCR analysis of the aqueous humor later turned out to be positive [32].

\section{Treatment and prognosis}

In most cases, the symptoms resolved with antivirals such as acyclovir/ valacyclovir/ famciclovir. The pain and fever subsided on taking analgesics and anti-inflammatory medications- acetaminophen, tramadol, and gabapentin. 
[18,19,21,22,24,25]. However, in others, oral steroids [19] were also prescribed. Pona et al. used no antiviral therapy, and gabapentin was only administered to relieve the pain [20]. The neurological complications resulting from VZV were treated with intravenous acyclovir and ganciclovir [31,32].

\section{Conclusion}

Such atypical presentations necessitate prompt clinical suspicion. Adequate isolation protocol is mandated in these patients. This will not only prevent transmission of COVID-19 but also avert the risk of mini-outbreaks of Chickenpox, which may further add to the current healthcare burden. We call upon the scientific committee to pour their insight into the matter and devise recommendations for Herpes Zoster vaccination in situations such as the given SARS CoV-2 pandemic. Although research is lacking, given the contagiousness of the VZV, we also recommend vaccination of family members and close contacts of such patients, especially in the pediatric age group.

Disclosures: There is no conflict of interest for all authors. Acknowledgements: None. Funding: None.

\section{References}

1. WHO. Q\&A: Influenza and COVID-19-similarities and differences. 2020.

2. Weiss SR, Leibowitz JL. Coronavirus pathogenesis. Advances in virus research. 81: Elsevier; 2011; 85-164. https://doi.org/10.1016/ B978-0-12-385885-6.00009-2

3. Drosten C, Günther S, Preiser W, Van Der Werf S, Brodt H-R, Becker S, et al. Identification of a novel coronavirus in patients with severe acute respiratory syndrome. New England journal of medicine. 2003; 348(20):1967-1976. https://doi.org/10.1056/NEJMoa030747

4. Zhu N, Zhang D, Wang W, Li X, Yang B, Song J, et al. A novel coronavirus from patients with pneumonia in China, 2019. New England Journal of Medicine. 2020. https://doi.org/10.1056/NEJMoa2001017

5. Kumar A, Arora A, Sharma P, Anikhindi SA, Bansal N, Singla V, et al. Clinical features of COVID-19 and factors associated with severe clinical course: a systematic review and meta-analysis. Available at SSRN 3566166. 2020. https://doi.org/10.2139/ssrn.3566166

6. Xu H, Zhong L, Deng J, Peng J, Dan H, Zeng X, et al. High expression of ACE2 receptor of 2019-nCoV on the epithelial cells of oral mucosa. International journal of oral science. 2020; 12(1):1-5. https://doi.org/10.1038/s41368-020-0074-X

7. Recalcati S. Cutaneous manifestations in COVID-19: a first perspective [published online ahead of print March 26, 2020]. J Eur Acad Dermatol Venereol.10.

8. Wollina U, Karadağ AS, Rowland-Payne C, Chiriac A, Lotti T. Cutaneous Signs in COVID-19 Patients: A Review. Dermatologic therapy. 2020.

9. Genovese G, Colonna C, Marzano AV. Varicella-like exanthem associated with COVID-19 in an 8-year-old girl: A diagnostic clue? Pediatric Dermatology. 2020. https://doi.org/10.1111/pde.14201

10. Marzano AV, Genovese G, Fabbrocini G, Pigatto P, Monfrecola G, Piraccini BM, et al. Varicella-like exanthem as a specific COVID19-associated skin manifestation: Multicenter case series of 22 patients. Journal of the American Academy of Dermatology. 2020. https://doi.org/10.1016/j.jaad.2020.04.044

11. Mueller NH, Gilden DH, Cohrs RJ, Mahalingam R, Nagel MA. Varicella zoster virus infection: clinical features, molecular pathogenesis of disease, and latency. Neurologic clinics. 2008; 26(3):675-697. https://doi.org/10.1016/j.ncl.2008.03.011

12. Merad M, Martin JC. Pathological inflammation in patients with COVID-19: a key role for monocytes and macrophages. Nature Reviews Immunology. 2020; 1-8. https://doi.org/10.1038/s41577-020-0353-y

13. Huang C, Wang Y, Li X, Ren L, Zhao J, Hu Y, et al. Clinical features of patients infected with 2019 novel coronavirus in Wuhan, China. The lancet. 2020; 395(10223):497-506. https://doi.org/10.1016/S0140-6736(20)30183-5

14. Wang F, Nie J, Wang H, Zhao Q, Xiong Y, Deng L, et al. Characteristics of peripheral lymphocyte subset alteration in COVID-19 pneumonia. The Journal of infectious diseases. 2020; 221(11):1762-1769. https://doi.org/10.1093/infdis/jiaa150

15. Wei L, Zhao J, Wu W, Zhang Y, Fu X, Chen L, et al. Decreased absolute numbers of CD3+ T cells and CD8+ T cells during aging in herpes zoster patients. Scientific Reports. 2017; 7(1):1-8. https://doi.org/10.1038/s41598-017-15390-w

16. Li H, Liu L, Zhang D, Xu J, Dai H, Tang N, et al. SARS-CoV-2 and viral sepsis: observations and hypotheses. The Lancet. 2020. https:// doi.org/10.1016/S0140-6736(20)30920-X

17. Soyuncu S, Berk Y, Eken C, Gulen B, Oktay C. Herpes zoster as a useful clinical marker of underlying cell-mediated immune disorders. Ann Acad Med Singap. 2009; 38(2):136-138.

18. Saati A, Al-Husayni F, Malibari AA, Bogari AA, Alharbi M. Herpes Zoster Co-Infection in an Immunocompetent Patient With COVID-19. Cureus. 2020; 12(7). https://doi.org/10.7759/cureus.8998

19. 19. Elsaie ML, Youssef EA, Nada HA. Herpes zoster might be an indicator for Latent COVID 19 infection. Dermatologic Therapy. 2020:e13666.

20. Pona A, Jiwani RA, Afriyie F, Labbe J, Cook PP, Mao Y. Herpes zoster as a potential complication of coronavirus disease 2019. Dermatologic Therapy. 2020. https://doi.org/10.1111/dth.13930

21. de Freitas Ferreira ACA, Romão TT, SIlva Macedo Y, Pupe C, Nascimento OJ. COVID-19 and herpes zoster co-infection presenting with trigeminal neuropathy. European Journal of Neurology. 2020. https://doi.org/10.1111/ene.14361

22. Tartari F, Spadotto A, Zengarini C, Zanoni R, Guglielmo A, Adorno A, et al. Herpes zoster in COVID-19-positive patients. International Journal of Dermatology. 2020. https://doi.org/10.1111/ijd.15001

23. Packwood R, Galletta G, Tennyson J. An unusual case report of covid-19 presenting with meningitis symptoms and shingles. Clinical Practice and Cases in Emergency Medicine. 2020; 4(3):316. https://doi.org/10.5811/cpcem.2020.4.47557

24. Elsaie ML, Nada HA. Herpes Zoster (shingles) complicating the course of COVID19 infection. Journal of Dermatological Treatment. 2020 (just-accepted); 1-7. https://doi.org/10.1080/09546634.2020.1782823

25. Shors AR. Herpes zoster and severe acute herpetic neuralgia as a complication of COVID-19 infection. JAAD case reports. 2020; 6(7):656-657. https://doi.org/10.1016/j.jdcr.2020.05.012 
26. Ertugrul G, Aktas H. Herpes zoster cases increased during COVID-19 outbreak. Is it possible a relation? Journal of Dermatological Treatment. 2020; 1(1). https://doi.org/10.1080/09546634.2020.1789040

27. Mahalingam R, Wellish M, Brucklier J, Gilden DH. Persistence of varicalla-zoster virus DNA in elderly patients with postherpetic neuralgia. Journal of neurovirology. 1995; 1(1):130-133 https://doi.org/10.3109/13550289509111018

28. Oster G, Harding G, Dukes E, Edelsberg J, Cleary PD. Pain, medication use, and health-related quality of life in older persons with postherpetic neuralgia: results from a population-based survey. The Journal of pain. 2005; 6(6):356-363. https://doi.org/10.1016/j. jpain.2005.01.359

29. Forbes HJ, Thomas SL, Smeeth L, Clayton T, Farmer R, Bhaskaran K, et al. A systematic review and meta-analysis of risk factors for postherpetic neuralgia. Pain. 2016; 157(1):30. https://doi.org/10.1097/j.pain.0000000000000307

30. Cao X. COVID-19: immunopathology and its implications for therapy. Nature reviews immunology. 2020; 20(5):269-270. https://doi org/10.1038/s41577-020-0308-3

31. Patel P, Undavia A, Choudry R, Zhang Y, Prabhu AM. COVID-19 associated with concomitant Varicella Zoster Viral Encephalitis. Neurology: Clinical Practice. 2020. https://doi.org/10.1212/CPJ.0000000000000902

32. Hassanpour K, Khorasanizadeh F, Ahmadieh H, Nabavi M, Daftarian N, Ramezani A. Varicella Zoster Virus Induced Acute Retinal Necrosis Following Acute Meningoencephalitis in a Patient with Presumed COVID-19. 2020 